\title{
Small Business Leadership and Ethical Attributes That Influence Employee Job Satisfaction
}

\author{
LaJuan Perronoski Fuller \\ Trident University International, Cypress, CA, USA \\ Email: lajuan.fuller@my.trident.edu
}

How to cite this paper: Fuller, L. P. (2022) Small Business Leadership and Ethical Attributes That Influence Employee Job Satisfaction. Open Journal of Business and Management, 10, 350-368.

https://doi.org/10.4236/ojbm.2022.101021

Received: December 1, 2021

Accepted: January 17, 2022

Published: January 20, 2022

Copyright $\odot 2022$ by author(s) and Scientific Research Publishing Inc. This work is licensed under the Creative Commons Attribution International License (CC BY 4.0).

http://creativecommons.org/licenses/by/4.0/

\begin{abstract}
Organizational leadership studies acknowledge that leadership styles positively affect job satisfaction. Currently, there are limited ethical, theoretical studies to investigate the relationship with job satisfaction. Therefore, there is a need for additional ethical leadership theories to explain conditions that may improve on negative organizational phenomena. This study investigated the relationship between the foundational leadership theory and job satisfaction. Foundational leadership is an inward (internal) and outward (employee perceived) examination of ethical decisions based on integrity, assurance, and pragmatism. The findings were based on 330 full-time entry and mid-level employees between ages $18-60+$ across various industries in the United States. Cronbach's alpha confirmed that integrity, assurance, and pragmatism is reliable measurement for ethical leadership. Pearson correlation revealed that the foundational leadership attributes of integrity, assurance, and pragmatism significantly correlate with employee job satisfaction. Finally, multiple linear regression results determine that ethical leadership training programs can teach Foundational Leadership to create job satisfaction. However, recurring leadership training should reinforce foundational leadership assurance (FLA) to foster job satisfaction within the leader-member exchange relationship.
\end{abstract}

\section{Keywords}

Ethics, Leadership, Job Satisfaction, Small Business Management

\section{Introduction}

Leadership plays a positive role in shaping organizational outcomes such as job 
performance (Dimitriou \& DiGaetano, 2016; Dimitriou, 2018), organizational commitment (Bedi et al., 2016), and job satisfaction (Schwartz, 2016). These outcomes are directly related to employee behaviors and actions toward the organization. Recently studies have suggested that ethical leadership styles are responsible for achieving much of this success (Toytok \& Kapusuzoglu, 2016; Dimitriou, 2018, 2020). Despite limited theoretical research on ethical leadership, further exploration can explain the overall relationship with employee job satisfaction (Qing et al., 2019; Stamolampros et al., 2019).

Ethical leaders positively affect employee behavior and attitudes (Brown et al., 2005). Comparatively, ethical leaders are more likely to treat employees fairly (Brown, Trevino, \& Harrison, 2005) and care for their well-being (Schwepker \& Dimitriou, 2021). Employees who perceive leaders as ethical have higher trust and enthusiasm at work. Leadership's abilities to foster trust and create enthusiasm among employees are significant contributors to job satisfaction (Engelbrecht et al., 2017; Ko et al., 2018). Qing et al. (2019) confirmed that ethical leadership styles influence organizational employees' sense of satisfaction. Based on these findings, more research is needed better explain alternative ethical leadership styles and their influence on job satisfaction.

The study aims to fill gaps in current literature on behavioral ethics by advancing the foundational leadership theory (FLT). FLT is an ethical leadership approach developed by Fuller (2021a). FLT suggests that leaders who conduct an inward and outward examination of decisions based on integrity, assurance, and pragmatism are perceived as ethical by organizational employees, which significantly predicts organizational commitment (Fuller, 2021a) and work engagement (Fuller, 2021b). These previous studies suggest that foundational leadership integrity (FLI), assurance (FLA), and pragmatism (FLP) may provide further insight into the relationship between ethical leadership and job satisfaction.

Organizational leadership studies widely accept that leadership styles positively affect job satisfaction (Schwartz, 2016), and integrity is a highly sought-after quality. Thus, this research examines alternative ethical leadership styles with conditions that may improve these organizational phenomena (Joplin et al., 2019). Therefore, if employees perceive integrity, assurance, and pragmatism as ethical leadership qualities, these FLT attributes will likely positively associate with job satisfaction.

RQ1: Do foundational leadership integrity, assurance, and pragmatism have a positive relationship with employees' job satisfaction?

The remainder of this article is as follows. Section 2 reviews the literature on ethics, foundational leadership attributes, and job satisfaction. Section 3 describes the methodology and definitions for foundational leadership and job satisfaction. Sections 4 and 5 specify the quantitative method of analysis and model output results. Finally, Section 6 explains the analysis results and delivers a comprehensive discussion on the benefits of foundational leadership attributes 
and improving an employee's job satisfaction.

\section{Literature Review}

House (1976) and McCall (1986) introduced charismatic and transformational leadership theories. They proposed that different leadership processes and consequences influence employees (Bandura, 1986; Bass \& Riggio, 2006). Studies on ethical leadership concur that integrity, fairness, and honesty are essential to effective leadership in private and public sectors. Nonetheless, more attention has been given toward adaptations of systematic approaches to examine the meaning of ethical leadership (Hassan et al., 2014; Fehr et al., 2015).

Ethical leadership is a person's ability to demonstrate normatively appropriate conduct and promote such conduct through two-way communication, reinforcement, and decision-making (Brown et al., 2005). Personal actions and interpersonal relationships promote such behaviors. Trustworthy leaders are perceived as more ethical and enhance loyalty and commitment among employees (Babalola et al., 2016; Lam et al., 2016). Lin and Liu (2017) confirmed that trustworthiness is strongly associated with ethical leadership and job satisfaction.

Ethical leadership is distinct (Brown, Trevino, \& Harrison, 2005), and leaders can combine ethics with other leadership styles (Den Hartog \& Belschak, 2012). Brown, Trevino and Harrison (2005) confirmed that servant leaders and ethical leaders use communication, practice role modeling, and are altruistic. However, servant leaders pride themselves on self-reflection and organizational success. Comparatively, transformational leaders use integrity like ethical leadership styles. Unlike ethical leaders, transformational leaders focus primarily on vision and values, while ethical leaders are moral managers who perform ethical standards (Brown, Trevino, \& Harrison, 2005). Leaders who never compromise ethics continually put others first and significantly affect the employee-organization relationship.

Ethical leaders tend to keep employees focused on the importance of the job (Brown et al., 2005) and affect follower attitudes and behavior (Qing et al., 2019). FLT may further explain the influence of ethical leadership on job satisfaction. First, foundational leadership provides an inward (personal) and outward (employee perception) examination for decision-making. Ethical leadership who exhibits foundational leadership attributes will exhibit a fair and candid nature toward employees. CEOs and managers should rely on FLT to influence organizational commitment (Fuller, 2021a) and predict job satisfaction.

Job satisfaction is critical in retaining a skilled workforce. The extant scholarly thought substantiates a positive relationship between employee satisfaction, customer satisfaction, and corporate performance (Harter, Schmidt, \& Hayes, 2002; Huang, Li, Meschke, \& Guthrie, 2015; Symitsi, Stamolampros, \& Daskalakis, 2018). Job satisfaction is highly associated with job performance. Comparatively, each has a significant positive association with organizational citizenship behaviors. As a result, employees with job satisfaction are the driving force for productive companies (Whitman et al., 2010). Therefore, employee job satisfac- 
tion is one of the most studied parameters, emphasizing the value of health at the workplace (Di Fabio et al., 2020; Rukh et al., 2020).

Researchers have conducted meta-analyses on job satisfaction and well-being. The literature revealed that job satisfaction was a significant predictor of psychological health (Faragher et al., 2005) and subjective well-being (Bowling et al., 2010). Because foundational leadership predicted employee physiological bond to their organization (Fuller, 2021a), it is plausible that foundational leadership attributes are equally associated with job satisfaction.

FLT continues to advance our understanding of the ethic position theory (EPT) and the social exchange theory (SET). FLT suggests that ethical leadership consists of both an inward (personal) and outward (employee perception) examination of decisions. FLT advances EPT by defining ethical leaders as decision-makers whose choices consist of integrity, assurance, and pragmatism. Previous research by Fuller (2021a, 2021b) provided Cronbach's alpha score of >.93, which confirms that integrity (FLI), assurance (FLA), and pragmatism (FLP) effectively measures ethical leadership within FLT's paradigm. Comparatively, previous research validates that ethical leadership style by supporting studies that proved leadership is a significant predictor of organizational commitment (Aboramadan et al., 2019; Aboramadan \& Dahleez, 2020; Fuller, 2021a) and work engagement (Fuller, 2021b). Thus, foundational leadership's theoretical framework, which predicted organizational commitment and employee work engagement, should positively affect job satisfaction.

The moral self explains leadership's motivation to act ethically (Jennings et al., 2015). Additionally, studies on ethics confirm that employees perceive fairness as an essential ethical leadership quality (Brown, Trevino, \& Harrison, 2005). Foundational leadership integrity uses a 5-item scale based on fairness to fill the gap in the literature on lack of agreement on "what is integrity" (Leicht-Deobald et al., 2019). Foundational leadership suggests that integrity is an essential part of ethical leadership, viewed as trustworthy, caring, honest, and fair (Jordan et al., 2017). Furthermore, integrity enhances follower perception (Ming et al., 2020) and is likely to influence job satisfaction.

Moral stress on employees increases their anxiety and uncertainty on the job (Reynolds, 2008; Daniels, Diddams, \& Van Duzer, 2011). Additionally, role conflict and role ambiguity (employees become uncertain about expectations) negatively impact job satisfaction (Karatepe \& Sokmen, 2006; Yang \& Wei, 2017) by increasing employee stress. Unfortunately, higher stress levels reduce job performance and satisfaction (Halkos \& Bousinkas, 2010; Shahid, 2012; Shukla \& Srivastava, 2016). Foundational leadership suggests that assurance reduces employee anxiety and uncertainty (Fuller, 2021a). Furthermore, foundational leadership assurance (FLA) explains that ethical leaders are more likely to reflect moral attentiveness, awareness, and identity (Lützén et al., 2010; Fuller, 2021a). Therefore, leaders may consider FLA a suitable alternative for reducing stress and anxiety, impacting job satisfaction. 
FLT explains that a one-size-fits-all approach to ethical leadership is ineffective in an organization. FLT addresses the social exchange theory (SET) and labels pragmatism as fundamental (Homans, 1961). According to Jordan (2019), pragmatism is a reflective quality and complements ethical leadership decision-making (Winter, 2013). Previous studies reveal how pragmatic forms of leadership have a positive relationship with employee dedication (Anderson \& Sun, 2017). Therefore, it is plausible that employee dedication promotes job satisfaction. Foundational leadership pragmatism (FLP) builds on our knowledge of SET, and this analysis will explain the link between ethical leadership and employee job satisfaction.

It is significant to note that previous studies validate that job satisfaction is an antecedent of organizational commitment and positively impacts employee job satisfaction (Barnes et al., 2015; Charni et al., 2019). Comparatively, scholars continue to have a standing interest in employee job satisfaction associated with attitudinal and behavioral outcomes (Judge \& Bono, 2001; Rich et al., 2010), such as organizational commitment (Chordiya et al., 2017). Because FLT influences employee organizational commitment (Fuller, 2021a) and employee work engagement (Fuller, 2021b), Figure 1 includes the conceptual model for foundational leadership and job satisfaction to investigate the following hypotheses:

$\mathrm{H} 1_{\mathrm{a}}$ : Foundational leadership's integrity, assurance, and pragmatism have no relationship with employee job satisfaction.

$\mathrm{H}_{\mathrm{b}}$ : Foundational leadership's integrity, assurance, and pragmatism positively affect job satisfaction.

$\mathrm{H} 2_{\mathrm{a}}$ : Foundational leadership integrity has no relationship with employee job satisfaction.

$\mathrm{H} 2_{\mathrm{b}}$ : Foundational leadership integrity positively affects employee job satisfaction.

$\mathrm{H} 3_{\mathrm{a}}$ : Foundational leadership assurance has no relationship with employee job satisfaction.

$\mathrm{H} 3_{\mathrm{b}}$ : Foundational leadership assurance positively affects employee job satisfaction.

$\mathrm{H} 4_{\mathrm{a}}$ : Foundational leadership pragmatism has no relationship with employee job satisfaction.

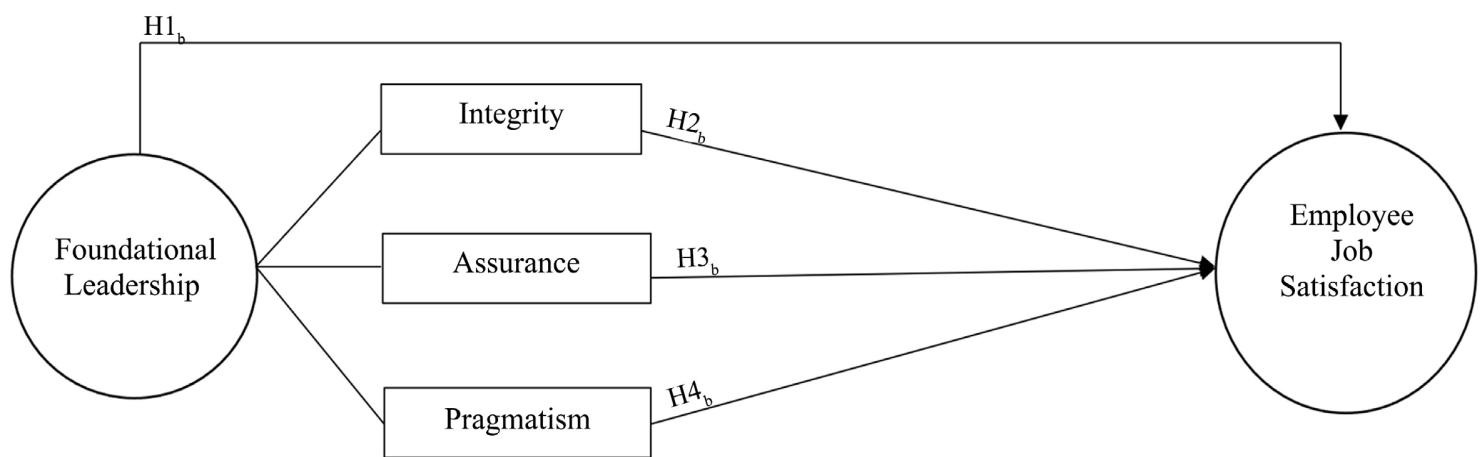

Figure 1. Foundational leadership and job satisfaction conceptual model. 
$\mathrm{H} 4_{\mathrm{b}}$ : Foundational leadership pragmatism has a positive relationship with employee job satisfaction.

\section{Methodology}

The methodology section describes the overall validity and reliability of FLT (IV) and job satisfaction (DV). This cross-sectional, quantitative study collects and analyzes data that further explain the relationship between FLT and job satisfaction. FLT is measured using a 15-item scale by Fuller (2021a). Job satisfaction is measured using a 3-item scale by Cammann et al. (1983), and Harari et al. (2018). This research randomly selects a sample from a population of full-time entry and mid-level employees in the small business sector across the United States. Work data from the US Department of Labor, current as of June 2020, a margin of error between $4 \%-6 \%$, and sample size formula by Cochran (1977) will determine the overall reliability of the sample population.

This research will use Cronbach's alpha to measure the scale reliability of FLT and Job Satisfaction. Additionally, Pearson correlation will determine the relationship between FLT and Job Satisfaction. These results tested the assumptions of normality, homoscedasticity, outliers, and regression paths. However, there was only one predictor variable. Thus, multicollinearity does not apply, and Variance Inflation Factors (VIF) as not considered for analysis. Finally, linear regression model output provided further insight into the positive or negative strength between the FLT and Job Satisfaction. This cross-sectional, quantitative study collects and analyzes the hypothesized relationships between FLT, FLI, FLA, FLP, and job satisfaction.

\section{Definition of Terms}

FLT measures leadership integrity, assurance, and pragmatism for ethical leaders. A 15-item seven-point Likert-type scale measures FLT. For example, "I trust leadership decisions that promote job security." Each measurement was based on a seven-point Likert-typed scale $(1=$ strongly disagree, $7=$ strongly agree) with a previous Cronbach's alpha of .93 (Fuller, 2021a) and .95 (Fuller, 2021b).

FLI is an employee's perception of fairness, and each participant will indicate their extent of agreement with each item on a seven-point Likert-typed scale ( $1=$ strongly agree, 7 = strongly disagree). For example, a leader's decisions should NOT be based on unsupported personal opinions. FLA measures employee perception of reassurance using a 5-item scale. For example, leaders should consider the amount of anxiety their decisions may cause. FLP measures employee perception of leadership decisions that are practical, easy to understand and help meet organizational goals. For example, a leader's decision should be realistic and achievable on the job.

Cammann et al.'s (1983) provide 3-items for Job Satisfaction. Harari et al. (2018) validate the measurement scale's accuracy. For example, all in all, I am 
satisfied with my job". The Cronbach's Alpha noted for this scale is .86. Previous research suggests that age and gender may have a bearing on job satisfaction (e.g., Kotur \& Anbazhagan, 2014). Therefore, age and gender will be control variables to determine FLT's overall influence on job satisfaction. Definitions are in Table 1.

\section{Method of Analysis}

The analysis requires 267 - 600 participants to achieve an acceptable margin of error between $4 \%$ - $6 \%$ of approximately $135 \mathrm{M}$ full-time employees in the small business sector. This quantitative study collected and analyzed data based on 330 completed surveys from full-time entry and mid-level employees in the small business sector across the United States. Part-time or seasonal employees or self-employed persons did not participate. The survey was sent via SurveyMon$\mathrm{key}^{\mathrm{TM}}$; each participant was randomly selected and required to read instructions before responding to the survey. Participants who selected "I do not agree" were diverted to a screen stating, "Thank you for your participation." Participants who selected "I agree to participate" were given access to the survey after signing informed consent.

Each response was given under anonymous conditions, and no personally identifiable information (PII) was collected. The survey asked respondents to indicate a level of agreement of FLT and job satisfaction ( $1=$ strongly disagree to 7 $=$ strongly agree). Cronbach's alpha was used to validate each scale. Pearson correlation provided insight into potential relationships between FLT and job satisfaction. Finally, linear regression was used to evaluate the strength of the relationship.

\section{Results}

Summary statistics were calculated based on responses from 330 participants from north, south, east, and western regions throughout the US Participants answered questions to measure FLT and job satisfaction. A summary of statistics for FLT (integrity, assurance, and pragmatism) and job satisfaction can be found in Table 2.

Table 1. Definition of terms.

\begin{tabular}{ll}
\hline \multicolumn{1}{c}{ Measurement } & \multicolumn{1}{c}{ Definition } \\
\hline $\begin{array}{l}\text { Foundational } \\
\text { Leadership-Integrity }\end{array}$ & $\begin{array}{l}\text { Fairness in decision-making is not based on biases, personal } \\
\text { favors, gifts, and/or unsupported opinions (Fuller, 2021a). } \\
\text { Foundational }\end{array}$ \\
$\begin{array}{l}\text { Leadership-Assurance } \\
\text { Foundational Leadership } \\
\text { security and reducing anxiety/stress (Fuller, 2021a). }\end{array}$ & $\begin{array}{l}\text { Easy to understand and practical decisions help employees } \\
\text { meet/exceed organizational goals (Fuller, 2021a). }\end{array}$ \\
Job Satisfaction & $\begin{array}{l}\text { The level of favorability of one's job (Cammann et al., 1983; } \\
\text { Harari et al., 2018). }\end{array}$ \\
\hline
\end{tabular}


Table 2. Summary statistics table for interval and ratio variables.

\begin{tabular}{ccccccc}
\hline Variable & $\mathrm{M}$ & $\mathrm{SD}$ & $\mathrm{n}$ & $\mathrm{SE}$. & Min & Max \\
\hline FLI1 & 6.30 & 1.41 & 330 & .078 & 1.00 & 7.00 \\
FLI2 & 6.43 & 1.16 & 330 & .064 & 1.00 & 7.00 \\
FLI3 & 6.44 & 1.20 & 330 & .066 & 1.00 & 7.00 \\
FLI4 & 6.28 & 1.22 & 330 & .67 & 1.00 & 7.00 \\
FLI5 & 6.27 & 1.15 & 330 & .064 & 1.00 & 7.00 \\
FLA1 & 6.21 & 1.25 & 330 & .069 & 1.00 & 7.00 \\
FLA2 & 6.23 & 1.22 & 330 & .067 & 1.00 & 7.00 \\
FLA3 & 6.02 & 1.23 & 330 & .068 & 1.00 & 7.00 \\
FLA4 & 6.26 & 1.02 & 330 & .056 & 1.00 & 7.00 \\
FLA5 & 5.93 & 1.22 & 330 & .067 & 1.00 & 7.00 \\
FLI1 & 6.04 & 1.31 & 330 & .072 & 1.00 & 7.00 \\
FLI2 & 5.77 & 1.32 & 330 & .073 & 1.00 & 7.00 \\
FLI3 & 5.95 & 1.31 & 330 & .072 & 1.00 & 7.00 \\
FLI4 & 5.89 & 1.36 & 330 & .075 & 1.00 & 7.00 \\
FLI5 & 5.82 & 1.36 & 330 & .075 & 1.00 & 7.00 \\
JS1 & 5.40 & 1.52 & 330 & .084 & 1.00 & 7.00 \\
JS2 & 5.31 & 1.55 & 330 & .085 & 1.00 & 7.00 \\
JS3 & 5.05 & .99 & 330 & .099 & 1.00 & 7.00 \\
\hline
\end{tabular}

Note: $\mathrm{n}=330$.

A Cronbach alpha coefficient was calculated for the FLT and Job Satisfaction to ensure that each question effectively measured each construct before conducting a Pearson correlation on the potential relationship between FLT and Job Satisfaction. The "scale if delete" function was selected for both measurement scales and suggested that deleting JS2 would yield a higher Cronbach's alpha score of .873. SPSS reliability statistics suggest FLT 15 was the strongest at .94 . Table 3 represents Cronbach Alpha results based on the 15-item scale for FLT and 2-item scale for Job Satisfaction. Both scales measure at $>.08$, representing good scale reliability based on guidelines by George and Mallery (2018).

FLT's 15-items were transformed into the IV labeled FLT, and Job Satisfaction 2-items were transformed into DV labeled JS. Then, a Pearson correlation analysis was conducted between FLT and JS. All assumptions were met for Pearson Correlation testing per Conover and Iman (1981). A significant positive correlation was observed between FLT and JS ( $\mathrm{RP}=.365, p<.001$, 95\% [CI]). This correlation indicates that as FLT increases, Job Satisfaction tends to increase. Table 4 presents the results of the correlation.

Furthermore, a linear regression analysis was conducted to assess whether FLT significantly predicted JS. All assumptions of normality, homoscedasticity, 
Table 3. Reliability table for FLT and job satisfaction.

\begin{tabular}{ccc}
\hline Variable & Item & $\boldsymbol{\alpha}$ \\
\hline FLT. & 15 & .937 \\
Job Satisfaction & 2 & .873 \\
\hline
\end{tabular}

Note: $\mathrm{n}=330$.

Table 4. Pearson correlation results for FLT and job satisfaction.

\begin{tabular}{ccc}
\hline Combination & RP. & $p$ \\
\hline FLT-JS & .36 & $<.001$ \\
\hline
\end{tabular}

Note: $\mathrm{n}=330$.

multicollinearity, and outliers were met. The linear regression model results were significant and indicated that FLT significantly predicted work engagement, $\mathrm{B}=.073, \mathrm{t}(344)=6.725, p<.001$. These results indicate that a one-unit increase of FLT will increase the value of JS by .073 units on average. Table 5 summarizes the regression model.

FLT has a significant but low regression weight on JS. Therefore, integrity (5-items), assurance (5-items), and pragmatism (5-items) were studied individually to explore in more detail the influence on employee's job satisfaction. The Cronbach's alpha coefficient was evaluated using the guidelines suggested by George and Mallery (2018) where $>.9$ excellent, $>.8$ good, $>.7$ acceptable, $>.6$ questionable, $>.5$ poor, and $\leq .5$ unacceptable. FLI, FLA, and FLP were $>.8$ or higher. Table 6 represents the Cronbach Alpha results.

Integrity 5-items were transformed to FLI, assurance 5-items to FLA and pragmatism 5-items to FLP. All assumptions were met for Pearson Correlation testing per Conover and Iman (1981), and a significant positive correlation was observed between FLI, FLA, and FLP on JS. This correlation indicates and confirms previous findings that as FLI, FLA, or FLP increases, Job Satisfaction still tends to increase. Table 7 presents the results of the correlation.

The multiple regression "Enter" analysis method was conducted to investigate FLT's integrity, assurance, and pragmatism ability to predict employee job satisfaction. The multiple linear regression model results were significant and indicated that FLI, FLA, and FLP significantly predicted job satisfaction. The results conclude that a one-unit increase of FLI will increase the value of job satisfaction by .18 units on average; FLA increases job satisfaction by .26 on average; FLP increases job satisfaction by .14 units on average. Table 8 summarizes the regression model results using the "Enter" method.

A stepwise linear regression method of regressing FLI, FLA, FLP was applied to determine the predictability of each ethical variable while simultaneously removing those that are not important. This stepwise regression should semi-automate our model by consecutively adding or removing either FLI, FLA, or FLP variables based on the t-statistics of their estimated coefficients. The results of this "Stepwise" 
Table 5. Linear regression results for FLT and job satisfaction.

\begin{tabular}{cccccc}
\hline Variable & $\mathrm{B}$ & $\mathrm{SE}$ & $\beta$ & $\mathrm{t}$ & $p$ \\
\hline (Intercept) & 3.98 & 1.012 & .00 & 3.934 & $<.001^{\star * *}$ \\
FLT & .073 & .11 & .348 & 6.725 & $<.001^{\star * *}$ \\
\hline
\end{tabular}

Note: $\mathrm{n}=330 ;{ }^{* *} p<.001$.

Table 6. Reliability table for FLI, FLA, and FLP.

\begin{tabular}{ccc}
\hline Variable & Item & $\boldsymbol{\alpha}$ \\
\hline FLI & 5 & .90 \\
FLA & 5 & .83 \\
FLP & 5 & .84 \\
\hline
\end{tabular}

Table 7. Pearson correlation results for FLT and job satisfaction.

\begin{tabular}{ccc}
\hline Combination & RP. & $p$ \\
\hline FLI-Job Satisfaction & .33 & $<.001^{* * *}$ \\
FLA-Job Satisfaction & .26 & $<.001^{\star * *}$ \\
FLP-Job Satisfaction & .36 & $<.001^{\star * *}$ \\
\hline
\end{tabular}

Note: ${ }^{* *} p<.001$.

Table 8. Regression model "Enter" method results for FLI, FLA, and FLP on job satisfaction.

\begin{tabular}{cccccc}
\hline Variable & $\mathrm{B}$ & SE. & $\beta$ & $\mathrm{t}$ & $p$ \\
\hline FLI & .18 & .02 & .334 & 6.427 & $<.000^{* * *}$ \\
FLA & .26 & .03 & .362 & 7.034 & $<.000^{* * *}$ \\
FLP & .14 & .02 & .259 & 4.847 & $<.000^{* * *}$ \\
\hline
\end{tabular}

Note: ${ }^{* *} p<.001$.

regression model provide a deeper understanding than ordinary multiple linear regression. Stepwise is used in conjunction with the "Enter" method to reveal the independent variable with the most potential and fine-tune the model. The model results suggest that when FLA is a constant, FLI and FLP are insignificant at predicting JS. The output indicates that a one-unit increase of FLA will increase the value of job satisfaction by .23 units on average. Therefore, leaders can prioritize "assurance" to increase job satisfaction. Table 9 summarizes the results of the "Stepwise" regression model.

An analysis of variance (ANOVA) determines whether there were significant differences in Job Satisfaction by gender and age. The ANOVA was examined based on an alpha value of .05. The results of the ANOVA were not significant, $\mathrm{F}(1,246)=1.78, p=.184$, indicating the differences in job satisfaction among the gender were all similar. However, age group ANOVA was significant at <.05. As a result, post hoc tests were conducted on age groups (Table 10). 
Table 9. Multiple regression "Stepwise" model for FLI, FLA, and FLP on job satisfaction.

\begin{tabular}{cccc}
\hline Variable & $\mathrm{B}$ & $\mathrm{t}$ & $p$ \\
\hline FLA & .23 & 7.034 & $<.001^{\star * *}$ \\
FLI & .13 & 1.458 & $<.361$ \\
FLP & -.35 & -.446 & $<.429$ \\
\hline
\end{tabular}

Note: ${ }^{* *} p<.001$.

Table 10. Analysis of variance table for job satisfaction by gender.

\begin{tabular}{ccccc}
\hline Term & SS. & df & F & $p$ \\
\hline Gender & 216.82 & 1 & 2.150 & .144 \\
Age & 2669.59 & 3 & 3.439 & .016 \\
\hline
\end{tabular}

Note: $\mathrm{n}=330$.

A post hoc test was conducted and revealed that age groups 1 and 3 had a $p$-value of .017. There were no significant values between the remaining age groups. Therefore, gender does not have a significant influence on job satisfaction. However, there is a significant difference among group responses between Groups 1 and 3. Table 7 represents Age Group demographics (Table 11).

Figure 2 summarizes the model results for FLT, FLI, FLA, FLP, and Job Satisfaction.

Table 12 summarizes the hypotheses testing results for FLT, FLI, FLA, FLP, and Job Satisfaction.

\section{Discussion}

This study has two theoretical contributions. First, FLT suggests that ethical leadership is an employee's perception of a leader's decision-making integrity, assurance, and pragmatism. Results revealed that FLT has a positive relationship with job satisfaction at .35 . However, this represents a minimal effect size on job satisfaction. These results confirm that integrity may have a mediating relationship with job satisfaction (Lin \& Liu, 2017). FLI was studied individually on job satisfaction. Research confirms that FLI positively correlates with a regression prediction on job satisfaction at .26. Leaders who conduct an inward (self) and outward (employee perceived) examination of choices based on FLI will recognize a slight increase in employee job satisfaction.

Due to leadership, employees with higher stress levels have lower job satisfaction (Halkos \& Bousinkas, 2010; Shahid, 2012; Shukla \& Srivastava, 2016). Foundational leadership confirmed that assurance might reduce employee anxiety and uncertainty (Fuller, 2021a), explaining the positive relationship and influence on job performance. Like FLI, FLA has a small but significant positive relationship with job satisfaction at .26. Additionally, FLA confirms that ethical leaders are more likely to reflect employees' moral attentiveness, awareness, and 
Table 11. Age group summary demographic.

\begin{tabular}{ccc}
\hline Age Group & Responses & $\mathrm{n}$ \\
\hline Group 1 $(18-29)$ & $22 \%$ & 78 \\
Group 2 $(30-44)$ & $25.7 \%$ & 91 \\
Group 3 $(45-60)$ & $33.3 \%$ & 118 \\
Group 4 (>60) & $18.9 \%$ & 67 \\
\hline
\end{tabular}

Note: $\mathrm{n}=330$.

Table 12. Hypothesis testing results for FLT and job satisfaction.

$$
\text { Hypotheses }
$$

$\mathrm{H1} 1_{\mathrm{a}}$ : Foundational leadership's integrity, assurance, and pragmatism have no relationship with employee job satisfaction.

Reject

$\mathrm{H} 1_{\mathrm{b}}$ : Foundational leadership's integrity, assurance, and pragmatism positively affect job satisfaction.

Accept $^{* * *}$

$\mathrm{H} 2_{\mathrm{a}}$ : Foundational leadership integrity has no relationship with employee job satisfaction.

Reject

$\mathrm{H} 2$ b: Foundational leadership integrity positively affects employee job satisfaction.

Accept $^{* * *}$

$\mathrm{H} 3_{\mathrm{a}}$ : Foundational leadership assurance has no relationship with employee job satisfaction.

Reject

$\mathrm{H} 3_{\mathrm{b}}$ : Foundational leadership assurance positively affects employee job satisfaction.

Accept $^{* * *}$

$\mathrm{H} 4_{\mathrm{a}}$ : Foundational leadership pragmatism has no relationship with employee job satisfaction.

Reject

$\mathrm{H} 4 \mathrm{~b}$ : Foundational leadership pragmatism has a positive relationship with employee job satisfaction.

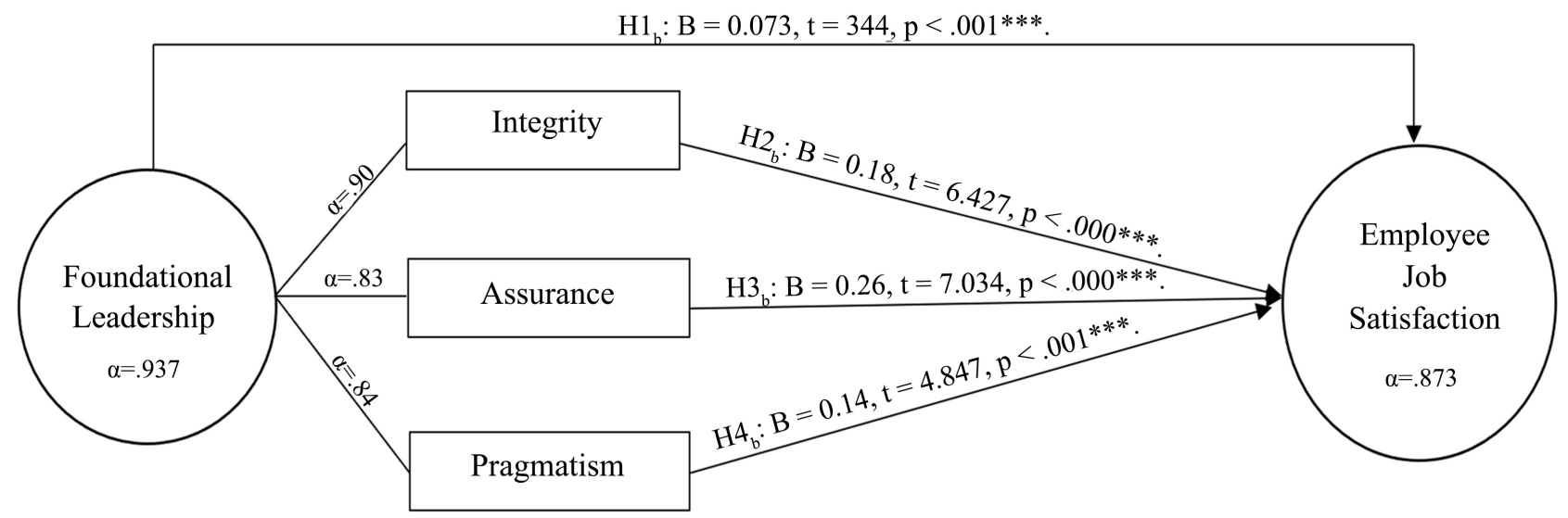

Figure 2. Foundational leadership and job satisfaction model results $\left({ }^{* *} p<.001\right)$. 
identity (Lützén et al., 2010; Fuller, 2021a), which provides a better understanding of why ethical leadership predicts employees' job satisfaction.

Next, previous research suggested that pragmatic forms of leadership may have a positive relationship with job satisfaction. Pearson correlation confirms a small but significant relationship with job satisfaction at .36. Additionally, linear regression output confirms that as FLP increases, job satisfaction tends to increase. Therefore, employees who perceive leadership decisions as being pragmatic are likely to be more satisfied on the job. The findings from this research on pragmatism support previous research that pragmatism contributes to job satisfaction (Chen et al., 2017).

Organizational leadership's ability to inspire and empower employees promote job satisfaction (Jordan et al., 2017). Inspirational leadership should use integrity, assurance, and pragmatism which influences organizational commitment (Fuller, 2021a), employee work engagement (Fuller, 2021b), and job satisfaction. These practical implications suggest that foundational leadership can be used with other leadership styles to improve job satisfaction. For example, transformational leadership is an approach that causes an extraordinary change in individuals and social systems. However, transformational leadership does not account for morals and ethics. Therefore, organizations can teach leaders to rely on foundational leadership as an ethical approach to examine their actions and behaviors to pursue change. Based on the findings from this research, organizations can continue to focus on training leaders and employees on ethical behaviors (Babalola et al., 2016; Qing et al., 2019) using FLT's inward (personal) and outward (employee perception) examination of decisions based on integrity, assurance, and pragmatism.

Kotur and Anbazhagan (2014) suggested that age and gender may have a bearing on job satisfaction. The results from this research determined that gender differences were not significant. However, there is a significant difference among responses between Employee Age Group 1 (18 - 29) and Group 2 (45 - 60). These ANOVA results partially supported Kotur and Anbazhagan (2014). However, employees who have feelings towards a sense of control (influence and worth) possess a higher level of job satisfaction (Aydogmus et al., 2018). Older employees may feel a stronger sense of control than younger employees. Trust relationships may explain the significant difference between younger and older employees' satisfaction on the job.

Foundational leadership is the inward and outward examination of a leader's decision-making actions. Leaders continue to play a positive role in job satisfaction (Schwartz, 2016), performance (Dimitriou \& DiGaetano, 2016), and organizational commitment (Bedi et al., 2016; Fuller, 2021a). The foundational leadership approach suggests that integrity, assurance, and pragmatism are valuable attributes in ethical decision-making. These three attributes establish ethical leadership guidelines. However, decisions that promote assurance (FLA) are deemed more salient for older employees (age 45 - 60). As a result, FLA con- 
firms that older employees perceive ethical leaders as reflecting moral attentiveness, awareness, and identity (Lützén et al., 2010; Fuller, 2021a). The investigation reveals that ethical forms of leadership are directly related to most organizational outcomes, and ethical leadership qualities continue to influence organizational success (Dimitriou, 2018, 2020). Therefore, the findings add to the literature and fill the gap in theoretical research on ethical leadership and job satisfaction (Qing et al., 2019; Stamolampros et al., 2019).

\section{Conclusion}

The research findings suggest that leaders should consider FLT ethical leadership practices to influence job satisfaction. The results indicated that FLT positively affects job satisfaction, organizational commitment (Fuller, 2021a), and work engagement (Fuller, 2021b). Additionally, ethical leadership is one of the only practices used with alternative leadership styles. Therefore, organization leaders can potentially improve pre-existing leadership styles by coupling them with FLT attributes. Adopting these practices will likely add value and benefit the leader-member exchange relationship (LMX).

This research has limitations based on using a cross-sectional study method. Therefore, the relationship between FLT and job satisfaction may change over time. The 330 participants in this study might have yielded different ANOVA results if race or time on the job were control variables. Therefore, further studies should consider these variables to provide additional insight into employee feelings and job satisfaction. Additionally, there were possible sample biases in this investigation. First, it was impossible to measure the entire population; data were collected from a sample of 330 full-time employees to reduce this bias and fall within an acceptable margin of error. Participants could have rushed or not have answered each question thoroughly. The survey contained only 19 one-sentence items to address variables to mitigate this possibility. Furthermore, each item is derivative from previously acceptable studies to decrease survey bias.

Additional research should address trustworthiness as a mediator or moderator between FLT and job satisfaction. Additionally, alternative ethical leadership styles may contribute to a deeper understanding of integrity, assurance, and pragmatic forms of leadership on employees' feelings toward job satisfaction. Gender was examined and showed no significant effect on job satisfaction. However, more research is needed to determine how other demographic categories such as income level and geographical location may influence the leader-member exchange on job satisfaction.

There was a need to establish alternative ethical leadership theories (van Knippenberg \& Sitkim, 2013; Pohan et al., 2019). FLT filled that need in the literature and confirmed that ethical leadership positively influences job satisfaction. This investigation concludes that ethical leaders who treat employees fairly (Brown, Trevino, \& Harrison, 2005) improve employee well-being (Schwepker \& 
Dimitriou, 2021) and is a significant contributor to job satisfaction (Engelbrecht et al., 2017; Ko et al., 2018). Professional development programs should train leaders and managers to conduct inward and outward examinations based on integrity, assurance, and pragmatism to establish ethical leadership principles that promote job satisfaction, organizational commitment (Fuller, 2021a), and employee work engagement (Fuller, 2021b). Despite limited theoretical research on ethical leadership, foundational leadership integrity, assurance, and pragmatism contribute to understanding the leader-member relationship concerning job satisfaction (Qing et al., 2019; Stamolampros et al., 2019).

\section{Conflicts of Interest}

The author declares no conflicts of interest regarding the publication of this paper.

\section{References}

Aboramadan, M., \& Dahleez. K. (2020). Leadership Styles and Employees' Work Outcomes in Nonprofit Organizations: The Role of Work Engagement. Journal of Management Development, 39, 869-893. https://doi.org/10.1108/JMD-12-2019-0499

Aboramadan, M., Hassi, A., Alharazin, H. J., Dahleez, K. A., \& Albashiti, B. (2019). Volunteering Drivers and Continuation Will: The Role of Engagement. The Journal of Management Development, 38, 405-420. https://doi.org/10.1108/JMD-02-2019-0057

Anderson, M., \& Sun, P. (2017). Reviewing Leadership Styles: Overlaps and the Need for a New Full Range Theory. International Journal of Management Reviews, 19, 76-96. https://doi.org/10.1111/ijmr.12082

Aydogmus, C., Metin Camgoz, S., Ergeneli, A., \& Tayfur Ekmekci, O. (2018). Perceptions of Transformational Leadership and Job Satisfaction: The Roles of Personality Traits and Psychological Empowerment. Journal of Management \& Organization, 24, 81-107. https://doi.org/10.1017/jmo.2016.59

Babalola, M. T., Stouten, J., \& Euwema, M. (2016). Frequent Change and Turnover Intention: The Moderating Role of Ethical Leadership. Journal of Business Ethics, 134, 311-322. https://doi.org/10.1007/s10551-014-2433-Z

Bandura, A. (1986). Fearful Expectations and Avoidant Actions as Coeffects of Perceived Self-Inefficacy. American Psychologist, 41, 1389-1391. https://doi.org/10.1037/0003-066X.41.12.1389

Barnes, D. C., Ponder, N., \& Hopkins, C. D. (2015). The Impact of Perceived Customer Delight on the Frontline Employee. Journal of Business Research, 68, 433-441.

https://doi.org/10.1016/j.jbusres.2014.06.005

Bass, B. M., \& Riggio, R. E. (2006). Transformational Leadership (2nd ed.). Lawrence Erlbaum Associates Publishers. https://doi.org/10.4324/9781410617095

Bedi, A., Alpaslan, C. M., \& Green, S. (2016). A Meta-Analytic Review of Ethical Leadership Outcomes and Moderators. Journal of Business Ethics, 139, 517-536. https://doi.org/10.1007/s10551-015-2625-1

Bowling, N. A., Wang, Q., Tang, H. Y., \& Kennedy, K. D. (2010). A Comparison of General and Work-Specific Measures of Core Self-Evaluations. Journal of Vocational Behavior, 76, 559-566. https://doi.org/10.1016/j.jvb.2010.01.008

Brown, M. E., Trevino, L. K., \& Harrison, D. (2005). Ethical Leadership: A Social Learn- 
ing Perspective for Construct Development and Testing. Organiztional Behavior and Human Decision Processes, 97, 117-134. https://doi.org/10.1016/j.obhdp.2005.03.002

Cammann, C., Fichman, M., Jenkins, D., \& Klesh, J. (1983). Assessing the Attitudes and Perceptions of Organizational Members. In S. Seashore, E. Lawler, P. Mirvis, \& C. Cammann (Eds.), Assessing Organizational Change: A Guide to Methods, Measures, and Practices. John Wiley.

Charni, H., Brun, I., \& Ricard, L. (2019). Impact of Employee Job Satisfaction and Commitment on Customer Perceived Value: An Original Perspective. International Journal of Bank Marketing, 38, 737-755. https://doi.org/10.1108/IJBM-03-2019-0097

Chen, S., Chiang, Y., \& Huang, Y. (2017). Exploring the Psychological Mechanisms Linking Work-Related Factors with Work-Family Conflict and Work-Family Facilitation among Taiwanese Nurses. International Journal of Human Resource Management, 28, 581-602. https://doi.org/10.1080/09585192.2015.1118140

Chordiya, R., Sabharwal, M., \& Goodman, D. (2017). Affective Organizational Commitment and Job Satisfaction: A Cross-National Comparative Study. Public Administration, 95, 178-195. https://doi.org/10.1111/padm.12306

Cochran, W. G. (1977). Sampling Techniques (3rd ed.). John Wiley \& Sons.

Conover, W. J., \& Iman, R. L. (1981). Rank Transformation as a Bridge between Parametric and Nonparametric Statistics. The American Statistician, 35, 124-129. https://doi.org/10.1080/00031305.1981.10479327

Daniels, D., Diddams, M., \& Van Duzer, J. (2011). A Magnetic Pull on the Internal Compass: The Moderating Effect of Response to Culture on the Relationship between Moral Identity and Ethical Sensitivity. Journal of Religion and Business Ethics, 2, Article No. 3 .

Den Hartog, D. N., \& Belschak, F. D. (2012). Work Engagement and Machiavellianism in the Ethical Leadership Process. Journal of Business Ethics, 107, 35-47. https://doi.org/10.1007/s10551-012-1296-4

Di Fabio, A., Cheung, F. M., \& Peiró, J. M. (2020). Editorial to Special Issue "Personality and Individual Differences and Healthy Organizations. Personality and Individual Differences, 166, Article ID: 110196. https://doi.org/10.1016/j.paid.2020.110196

Dimitriou, C. K. (2018). The Impact of Ethical Leadership on Organizational Culture, Employee Turnover Intention, and Firm Performance in the Hotel Industry.

Dimitriou, C. K. (2020). Adjusting Our Teaching Strategies, Material, and Techniques to the New Standards. In The Tourism Education Futures Initiatives (TEFI) 11-What's Tourism Got to Do with It? York St. John University.

Dimitriou, C. K., \& DiGaetano, J. (2016). Authentic Leadership and Psychological Well-Being of Hotel Employees at Work and the Role of Work Climate in This Relationship. In The 34th EuroCHRIE Conference 2016.

Engelbrecht, A. S., Heine, G., \& Mahembe, B. (2017). Integrity, Ethical Leadership, Trust and Work Engagement. Leadership \& Organization Development Journal, 38, 368-379. https://doi.org/10.1108/LODJ-11-2015-0237

Faragher, E. B., Cass, M., \& Cooper, C. L. (2005). The Relationship between Job Satisfaction and Health: A Meta-Analysis. Occupational and Environmental Medicine (London, England), 62, 105-112. https://doi.org/10.1136/oem.2002.006734

Fehr, R., Yam, K. C. S., \& Dang, C. (2015). Moralized Leadership: The Construction and Consequences of Ethical Leader Perceptions. Academy of Management Review, 40, 182-209. https://doi.org/10.5465/amr.2013.0358 
Fuller, L. (2021a). Foundational Leadership Theory: The Inward and Outward Approach to Examine Ethical Decision-Making. Open Journal of Leadership, 10, 79-94. https://doi.org/10.4236/ojl.2021.102006

Fuller, L. P. (2021b). Foundational Leadership Theory: An Ethical Leadership Approach to Developing Positive Employee Work Engagement. Open Journal of Business and Management, 9, 2136-2151. https://doi.org/10.4236/ojbm.2021.95113

George, D., \& Mallery, P. (2018). IBM SPSS Statistics 25 Step by Step. https://doi.org/10.4324/9781351033909

Halkos, G., \& Bousinakis, D. (2010). The Effect of Stress and Satisfaction on Productivity. International Journal of Productivity and Performance Management, 59, 415-431. https://doi.org/10.1108/17410401011052869

Harari, M. B., Thompson, A. H., \& Viswesvaran, C. (2018). Extraversion and Job Satisfaction: The Role of Trait Bandwidth and the Moderating Effect of Status Goal Attainment. Personality and Individual Differences, 123, 14-16. https://doi.org/10.1016/j.paid.2017.10.041

Harter, J. K., Schmidt, F. L., \& Hayes, T. L. (2002). Business-Unit-Level Relationship between Employee Satisfaction, Employee Engagement, and Business Outcomes: A Meta-Analysis. Journal of Applied Psychology, 87, 268-279.

https://doi.org/10.1037/0021-9010.87.2.268

Hassan, M. S., Abdul Rahman, R., \& Hossain, S. Z. (2014). Monitoring Family Performance: Family Ownership and Corporate Governance Structure in Bangladesh. Pricedia-Social and Behavioral Sciences, 145, 103-109. https://doi.org/10.1016/j.sbspro.2014.06.016

Homans, G. C. (1961). Social Behavior: Its Elementary Forms. Harcourt Brace Jovanovich.

House, R. J. (1976). A 1976 Theory of Charismatic Leadership: Working Paper Series 76-06. University of Toronto.

Huang, M., Li, P., Meschke, F., \& Guthrie, J. P. (2015). Family Firms, Employee Satisfaction, and Corporate Performance. Journal of Corporate Finance (Amsterdam, Nether lands), 34, 108-127. https://doi.org/10.1016/j.jcorpfin.2015.08.002

Jennings, P. L., Mitchell, M. S., \& Hannah, S. T. (2015). The Moral Self: A Review and Integration of the Literature. Journal of Organizational Behavior, 36, S104-S168. https://doi.org/10.1002/job.1919

Joplin, T., Greenbaum, R. L., Wallace, J. C., \& Edwards, B. D. (2019). Employee Entitlement, Engagement, and Performance: The Moderating Effect of Ethical Leadership. Journal of Business Ethics, 168, 813-826. https://doi.org/10.1007/s10551-019-04246-0

Jordan, G., Miglič, G., Todorović, I., \& Marič, M. (2017). Psychological Empowerment, Job Satisfaction and Organizational Commitment among Lecturers in Higher Education: Comparison of Six CEE Countries. Organizacija, 50, 17-32. https://doi.org/10.1515/orga-2017-0004

Jordan, J. B. (2019). Meta-Engagement: An Examination of Employee Engagement Antecedent Variable Interactions and the Impact on Engagement Outcomes.

Judge, T. A., \& Bono, J. E. (2001). Relationship of Core Self-Evaluations Traits: Self-Esteem, Generalized Self-Efficacy, Locus of Control, and Emotional Stability: With Job Satisfaction and Job Performance: A Meta-Analysis. Journal of Applied Psychology, 86, 80-92. https://doi.org/10.1037/0021-9010.86.1.80

Karatepe, O. M., \& Sokmen, A. (2006). The Effects of Work Role and Family Role Variables on Psychological and Behavioral Outcomes of Frontline Employees. Tourism 
Management (1982), 27, 255-268. https://doi.org/10.1016/j.tourman.2004.10.001

Ko, C., Ma, J., Bartnik, R., Haney, M., \& Kang, M. (2018). Ethical Leadership: An Integrative Review and Future Research Agenda. Ethics and Behavior, 28, 1-29. https://doi.org/10.1080/10508422.2017.1318069

Kotur, B. R., \& Anbazhagan, S. (2014). Influence of Age and Gender on the Performance. IOSR Journal of Business and Management, 16, 97-103. https://doi.org/10.9790/487X-165397103

Lam, J., Sutton, P., Kalkbrenner, A., Windham, G., Halladay, A., Koustas, E., Lawler, C., Davidson, L., Daniels, N., Newschaffer, C., \& Woodruff, T. (2016). A Systematic Review and Meta-Analysis of Multiple Airborne Pollutants and Autism Spectrum Disorder. PLoS ONE, 11, e0161851. https://doi.org/10.1371/journal.pone.0161851

Leicht-Deobald, U., Busch, T., Schank, C., Weibel, A., Schafheitle, S., Wildhaber, I., \& Kasper, G. (2019). The Challenges of Algorithm-Based HR Decision-Making for Personal Integrity. Journal of Business Ethics, 160, 377-392.

https://doi.org/10.1007/s10551-019-04204-w

Lin, C., \& Liu, M. (2017). Examining the Effects of Corporate Social Responsibility and Ethical Leadership on Turnover Intention. Personnel Review, 46, 526-550.

https://doi.org/10.1108/PR-11-2015-0293

Lützén, K., Blom, T., Ewalds-Kvist, B., \& Winch, S. (2010). Moral Stress, Moral Climate and Moral Sensitivity among Psychiatric Professionals. Nursing Ethics, 17, 213-224. https://doi.org/10.1177/0969733009351951

McCall Jr., M. W. (1986). Leadership and Performance beyond Expectations. The Free Press. https://doi.org/10.1002/hrm.3930250310

Ming, X., Bai, X., \& Lin, L. (2020). Kick the Cat: A Serial Crossover Effect of Supervisors' Ego Depletion on Subordinates' Deviant Behavior. Frontiers in Psychology, 11, Article No. 1314. https://doi.org/10.3389/fpsyg.2020.01314

Pohan, V., Schaufeli, W., Ivanova, T., \& Osin, E. (2019). Basic Psychological Need Satisfaction Mediates the Relationship between Engaging Leadership and Work Engagement: A Cross-National Study. Human Resource Development Quarterly, 30, 453-471.

Qing, M., Asif, M., Hussain, A., \& Jameel, A. (2019). Exploring the Impact of Ethical Leadership on Job Satisfaction and Organizational Commitment in Public Sector Organizations: The Mediating Role of Psychological Empowerment. Review of Managerial Science, 14, 1405-1432. https://doi.org/10.1007/s11846-019-00340-9

Reynolds, S. J. (2008). Moral Attentiveness: Who Pays Attention to the Moral Aspects of Life? Journal of Applied Psychology, 93, 1027-1041.

https://doi.org/10.1037/0021-9010.93.5.1027

Rich, B. L., Lepine, J. A., \& Crawford, E. R. (2010). Job Engagement: Antecedents and Effects on Job Performance. Academy of Management Journal, 53, 617-635. https://doi.org/10.5465/amj.2010.51468988

Rukh, G., Dang, J., Olivo, G., Ciuculete, D., Rask-Andersen, M., \& Schiöth, H. B. (2020). Personality, Lifestyle and Job Satisfaction: Causal Association between Neuroticism and Job Satisfaction Using Mendelian Randomisation in the UK Biobank Cohort. Translational Psychiatry, 10, Article No. 11. https://doi.org/10.1038/s41398-020-0691-3

Schwartz, M. S. (2016). Ethical Decision-Making Theory: An Integrated Approach. Journal of Business Ethics, 139, 755-776. https://doi.org/10.1007/s10551-015-2886-8

Schwepker, C. H., \& Dimitriou, C. K. (2021). Using Ethical Leadership to Reduce Job Stress and Improve Performance Quality in the Hospitality Industry. International Journal of Hospitality Management, 94, Article ID: 102860. 
https://doi.org/10.1016/j.ijhm.2021.102860

Shahid, M. N. et al. (2012). Work Stress and Employee Performance in Banking Sector Evidence from District Faisalabad Pakistan. Asian Journal of Business and Management Sciences, 1, 38-48.

Shukla, A., \& Srivastava, R. (2016). Development of Short Questionnaire to Measure an Extended Set of Role Expectation Conflict, Coworker Support and Work-Life Balance: The New Job Stress Scale. Cogent Business \& Management, 3, Article No. 1. https://doi.org/10.1080/23311975.2015.1134034

Stamolampros, P., Korfiatis, N., Chalvatzis, K., \& Buhalis, D. (2019). Job Satisfaction and Employee Turnover Determinants in High Contact Services: Insights from Employees' Online Reviews. Tourism Management, 75, 130-147.

https://doi.org/10.1016/j.tourman.2019.04.030

Symitsi, E., Stamolampros, P., \& Daskalakis, G. (2018). Employees' Online Reviews and Equity Prices. Economics Letters, 162, 53-55. https://doi.org/10.1016/j.econlet.2017.10.027

Toytok, E. H., \& Kapusuzoglu, S. (2016). Influence of School Managers' Ethical Leadership Behaviors on Organizational Culture: Teachers' Perceptions. Eurasian Journal of Educational Research, 16, 1-35. https://doi.org/10.14689/ejer.2016.66.21

van Knippenberg, D., \& Sitkin, S. B. (2013). A Critical Assessment of Charismatic-Transformational Leadership Research: Back to the Drawing Board? The Academy of Management Annals, 7, 1-60. https://doi.org/10.5465/19416520.2013.759433

Whitman, D. S., Van Rooy, D. L., \& Viswesvaran, C. (2010). Satisfaction, Citizenship Behaviors, and Performance in Work Units: A Meta-Analysis of Collective Construct Relations. Personnel Psychology, 63, 41-81. https://doi.org/10.1111/j.1744-6570.2009.01162.x

Winter, S. G. (2013). Habit, Deliberation, and Action: Strengthening the Microfoundations of Routines and Capabilities. Academy of Management Perspectives, 27, 120-137. https://doi.org/10.5465/amp.2012.0124

Yang, Q., \& Wei, H. (2017). The Impact of Ethical Leadership on Organizational Citizenship Behavior. The Moderating Role of Workplace Ostracism. Leadership and Organizational Development Journal, 39, 100-113. https://doi.org/10.1108/LODJ-12-2016-0313 